Milan Sova', Samuel Genzor', Vítězslav Kolek', Filip Čtvrtlík², Amjad Ghazal Asswad ${ }^{3}$, Ondřej Zela ${ }^{4}$, Zdeněk Tauber ${ }^{5}$

'Department of Respiratory Medicine, Faculty of Medicine and Dentistry, Palacky University Olomouc and University Hospital Olomouc, Czech Republic

${ }^{2}$ Department of Radiology, Faculty of Medicine and Dentistry, Palacky University Olomouc and University Hospital Olomouc, Czech

Republic

${ }^{3}$ Faculty of Medicine and Dentistry, Palacky University Olomouc, Czech Republic

${ }^{4}$ Department of Internal Diseases, Hospital Frydek-Mistek, Czech Republic

${ }^{5}$ Department of Histology and Embryology, Faculty of Medicine and Dentistry, Palacky University Olomouc, Czech Republic

\title{
Epicardial fat in patients with chronic obstructive pulmonary disease as a marker of high cardiovascular risk
}

The authors declare no financial disclosure

\begin{abstract}
Chronic obstructive pulmonary disease (COPD) and cardiovascular diseases (CVD) are commonly interconnected, and this coincidence negatively influences patients' mortality and morbidity. On the basis of the current available data originating mainly from cardiovascular studies epicardial fat (EF) has been proposed as a marker of cardiovascular risk.

This review is focused on a potential role of epicardial fat as a new biomarker for risk stratification of COPD patients.

Epicardial fat may present an important link between chronic obstructive pulmonary disease and cardiovascular diseases, mainly coronary artery disease.
\end{abstract}

Key words: epicardial fat, COPD, risk stratification

Adv Respir Med. 2018; 86: 314-318

\section{Introduction}

Chronic obstructive pulmonary disease (COPD) and cardiovascular diseases (CVD) are commonly interconnected, and this coincidence negatively influences patients' mortality and morbidity. In clinical practice it is usually hard to stratify COPD patients according to their cardiovascular risk, and nowadays we are looking for new biomarkers. Epicardial fat (EF) has been proposed as a marker of cardiovascular risk, and these days there are available data mainly from cardiovascular studies. Recently, as well as the relationship between COPD and EF has been studied. This review shows measurement methods of EF, pathophysiology, and data regarding EF in patients with COPD.

\section{Definitions}

\section{Epicardial fat}

Epicardial fat is the visceral thoracic fat deposition located between the myocardium and the visceral pericardium (Fig. 1) [1]. Epicardial fat is highly metabolically active - it produces many cytokines, which, for example, play a role in atherosclerosis progression [2]. Due to its activity, it should be distinguished from paracardial fat (adipose tissue located external to the parietal pericardium) and pericardial fat (paracardial fat with all the adipose tissue located internal to the parietal pericardium) [3]. In fact, the term pericardial fat is often used to describe all the adipose tissue located in the pericardial sac [4].

Address for correspondence: Samuel Genzor, Department of Respiratory Medicine, Faculty of Medicine and Dentistry, Palacky University Olomouc and University Hospital Olomouc, Czech Republic, e-mail: samuel.genzor@fnol.cz

DOI: 10.5603/ARM.a2018.0051

Received: 12.11 .2018

Copyright (C) 2018 PTChP

ISSN 2451-4934 


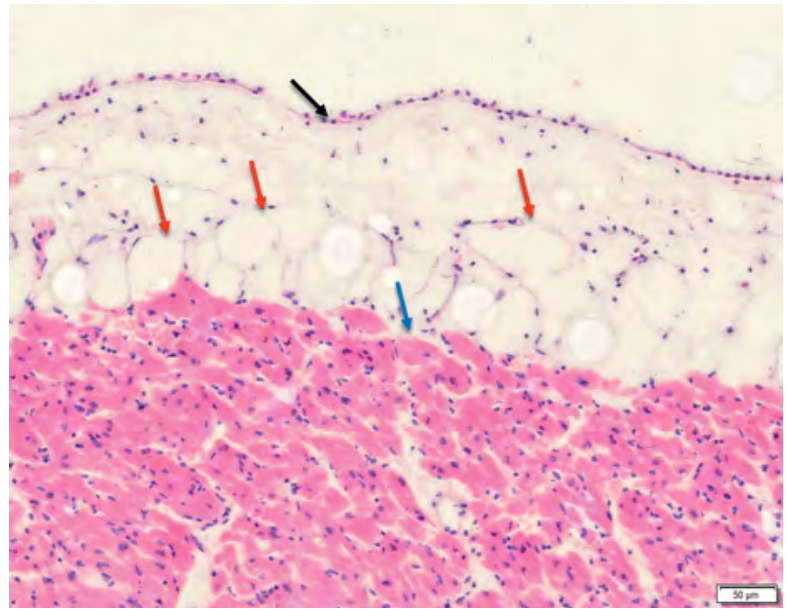

Figure 1. The figure shows a cross-section of the heart wall. Numerous adipocytes (red arrows) are present in the subepicardial connective tissue. The epicardium is marked with a black arrow, the myocardium (blue arrow) is captured at the bottom of the slide. Magnification $200 \times$

$\mathrm{EF}$ is usually found in atrioventricular and interventricular grooves extending to the apex of the heart, specifically between the myocardium and visceral pericardium $[5,6]$.

\section{Epicardial fat measurement}

For the measurement of epicardial fat, a few modalities could be used. The 'gold standard' is generally considered cardiac magnetic resonance (Fig. 2) [3]. This method offers excellent spatial resolution and is the only imaging modality in which volumetric quantification of epicardial fat has been validated ex vivo [7, 8]. The advantages are obvious - no radiation or iodinated contrast exposure. On the other hand, this method presents with many disadvantages amongst which are its high costs, time requirements and lower availability in some centres.

The chest computed tomography (CT) scan is an alternative that can be used for the measurement of epicardial fat (Fig. 3). This method was used widely in previous studies, especially because a chest CT was performed due to other indications like pulmonary embolism, calcium score measurement, emphysema quantification, etc. It offers high spatial resolution and attenuation value ranges can be defined to allow for either manual or semi-automatic quantification of adipose tissue [9, 10]. Advantages are a good resolution, excellent reproducibility and the possibility of volumetric quantification. The disadvantage is the exposure to both ionizing radiation and iodine-containing contrast.

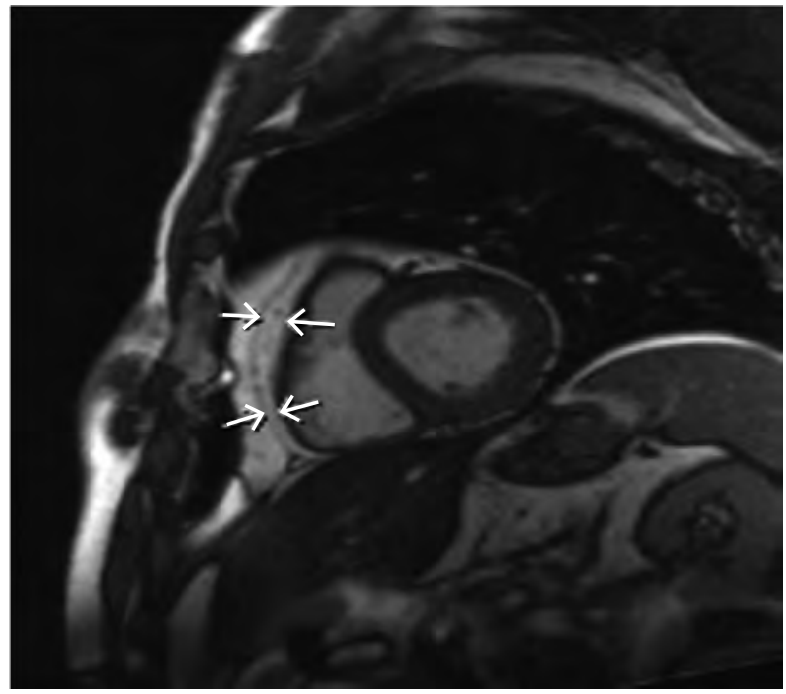

Figure 2. Cardiac magnetic resonance imaging assessment of periventricular epicardial fat. TrueFISP magnetic resonance image in short axis. End-diastole. Arrows depict epicardial fat

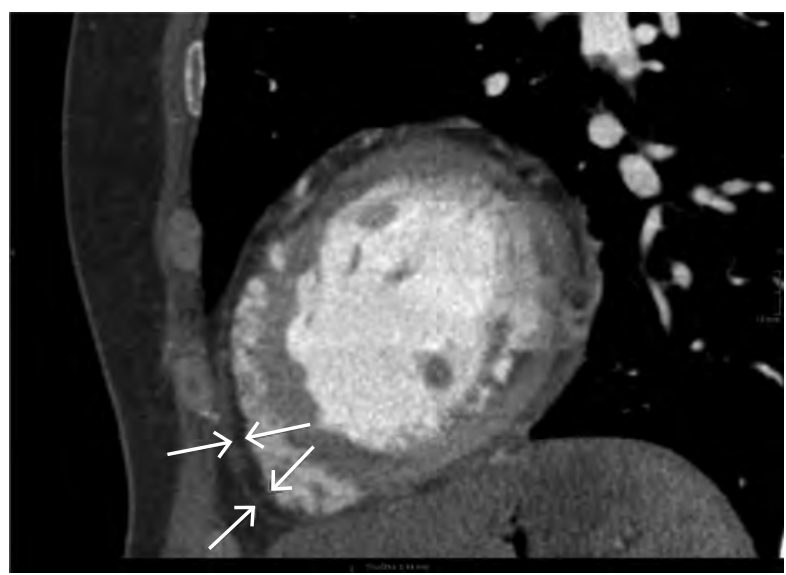

Figure 3. Computed tomography assessment of periventricular epicardial fat. Computed tomography after i.v. application of contrast agent in the parasagittal plain. End-diastole. Arrows depict epicardial fat

The third option is echocardiography, which is the most accessible and affordable imaging modality (Fig. 4). It is important to notice that 2D echocardiography does not offer measurement of the amount of epicardial fat like volumetric measurement during cardiac magnetic resonance or computed tomography imaging. This is possible only using 3D echocardiography, though this method is not widely available and it is time-consuming. Instead of the measurement of epicardial fat volume, epicardial fat thickness is used. EF is identified as a hypoechoic space anteriorly to the right ventricle wall, and its thickness is measured between the epicardial surface and pericardium identified by the sliding between these two layers [11]. This is measured over the free wall of the right ventricle in diastole 


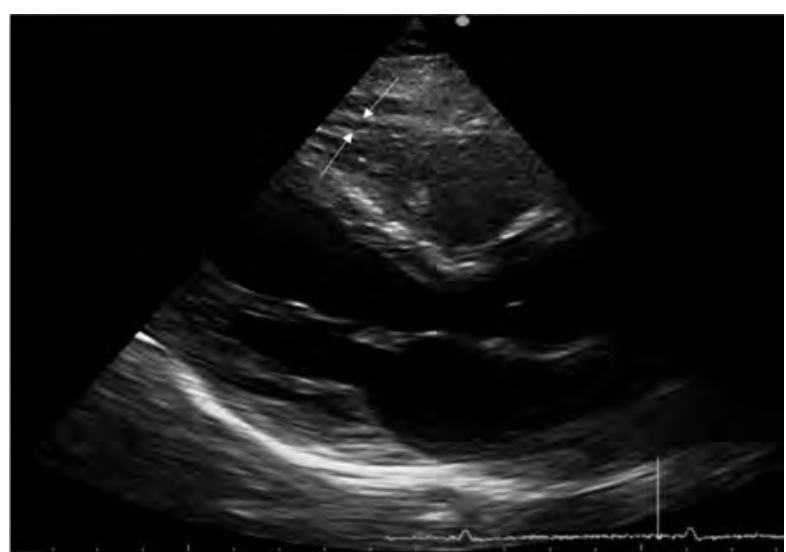

Figure 4. Echocardiography assessment of periventricular epicardial fat. End-diastole. Arrows depict epicardial fat

in three subsequent cardiac cycles [12]. According to some recommendations, measurement during systole is also used [13], but most authors use diastolic measurement to correlate with MRI and CT imaging outcomes. The most discussed aspect is the need to identify the pericardium as this can sometimes be very difficult, especially in an obese individual where good quality images are not usually available. On the other hand, in large population studies where there is a need for economic, safe and fast examinations, this approach to epicardial fat measurement seems justifiable, especially if we consider that a good correlation with MRI results has been shown $(\mathrm{r}=0.91, \mathrm{p}=0.001)[14]$.

\section{Epicardial fat physiology}

Epicardial fat originates from the splanchnopleuric mesoderm [15], in contrast to paracardial fat, which is derived from the primitive thoracic mesenchyme [16]. Epicardial fat is directly perfused by the coronary arteries and thus it has a direct paracrine effect on the myocardium [17]. Its functions include lipid storage for myocardial energy, thermoregulation and the protection of autonomic ganglia and nervous tissue [4]. There have also been discussions regarding further potential functions such as its effect on local distribution and regulation of vascular flow [16]; its role as an immune barrier in the protection of the myocardium and coronary arteries from inflammatory and pathogenic substances [18] as well as the mechanical protection of the coronary arteries.

$\mathrm{EF}$ is a highly metabolically active organ and a major source of anti-inflammatory and proinflammatory adipokines $[19,20]$.

Of the anti-inflammatory adipokines, the most important are adiponectin, adrenomedullin and omentin [21]. Adiponectin has antidiabetic, antiatherogenic, antioxidative and anti-inflammatory properties [22]. This adipokine also inhibits the production of tumour necrosis factor alpha (TNF- $\alpha$ ) and other inflammatory pathways in adipocytes and macrophages, producing an anti-inflammatory effect [23]. Also, EF produces a high amount of adrenomedullin, which is a potent vasodilator peptide [24]. It has also been proposed that adrenomedullin has antioxidant properties antagonising oxidative stress induced by angiotensin II [25].

$\mathrm{EF}$ is also a producer of pro-inflammatory adipokines like interleukin 1 (IL-1), interleukin 8 (IL-8), interleukin 6 (IL-6) and TNF- $\alpha$ [26, 27]. IL-6 is considered to be one of the key adipokines involved in atherosclerotic plaque development [28] as well as in insulin resistance [29]. TNF- $\alpha$ is another important adipokine produced by epicardial fat adipocytes. Its serum level is elevated in obese individuals where it actually worsens insulin resistance. TNF- $\alpha$ is also a potent vasoconstrictor [30]. It decreases adiponectin production and stimulates the production of other pro-inflammatory adipokines [31].

\section{Epicardial fat and cardiovascular diseases}

There are many studies available on epicardial fat in patients with CVD. Higher amounts of $\mathrm{EF}$ were found to be related to the presence of coronary syndromes and weakening of atheromatous plaques $[32,33]$. There is also data showing that individuals with a higher amount of EF have a more severe coronary plaques, indicating that the thickness of epicardial fat plays a key role in the progression of coronary atherosclerotic disease [34]. EF thickening is thus considered a risk factor of coronary plaque formation and their vulnerability [35]. An independent association between pericardial fat and cardiovascular risk factors, coronary calcification and the presence of carotid artery disease has also been demonstrated [11]. Further researches on atrial fibrillation (AF) and epicardial fat provide interesting data. Numerous studies support the association of epicardial fat with the presence of AF [36]. Data from the Framingham Heart Study suggests that EF volume is independently associated with prevalent AF [37]. Many pathophysiological mechanisms are discussed as possible causes. EF is a known source of reactive oxygen species [38], which may, according to some authors, play a role in the genesis of AF [4]. Autonomic dysfunction may also contribute, as the autonomic nervous system is thought, to play a crucial role in the initiation and 
maintenance of AF [39]. Ganglionated plexi are located in the epicardial fat and their dysfunction could lead to AF development as well [40].

\section{Epicardial fat and chronic obstructive pulmonary disease}

In the field of COPD and EF, only a few studies have been performed. Zagaceta et al. [1] enrolled 171 stable COPD patients (mostly stage I and II according to GOLD 2009 guidelines) and 70 controls (ex-smokers) in whom the amount of $\mathrm{EF}$ was measured using CT imaging. Multivariate analysis exploring the association of EF volume and COPD diagnosis, after adjusting for the Charlson Comorbidity Index, showed that the presence of COPD was a statistical predictor of EF volume ( $\beta$ coefficient 28.86; 95\% CI: 7.6-51.1; $\mathrm{p}=0.008$ ). Moreover, EF was independently associated with modifiable CVD risk factors like smoking history, BMI and decreased exercise capacity. As was shown in a previous study [41], a higher EF volume predicts higher CVD risk in community-based adults without a history of CVD. This could represent a strong link between COPD and CVD risk. There is also increasing evidence that adipose tissue is a significant contributor to the systemic inflammation load in COPD [42, 43]. Visceral fat plays a main role where adipose tissue dysfunction, including enhanced adipose tissue inflammation, was described and could contribute to the low-grade inflammation, which has been described in patients with COPD. For example, excessive visceral fat mass was positively associated with all-cause and cardiovascular disease mortalities as well as with a higher serum level of IL-6 [43]. It is unclear whether pulmonary impairment or poor lifestyle predispose to excessive visceral fat accumulation.

In another study, Kiraz et al. [44] enrolled a sample of 157 COPD patients and 45 controls where the epicardial fat thickness was measured using echocardiography. EF thickness was higher in the COPD patients in comparison with the controls $(\mathrm{p}<0.05)$. In the same study, an inverse correlation between the BODE index and EF thickness was found. Similarly, the study by Demir et al. [45] found higher EF thickness in those with COPD in comparison to healthy subjects $(p<0.001)$. However, the study by Kaplan et al. [12] paradoxically found EF thickness to be lower in patients with COPD and systolic dysfunction of the right ventricle.

The important aspect and possible future direction of research is the relationship between $\mathrm{EF}$ volume and different COPD phenotypes, as COPD is a highly heterogeneous disease, and the same cardiovascular risk cannot be presumed for all phenotypes.

Furthermore, data regarding the possible effect of bronchodilator treatment in the reduction of cardiovascular disease risk is missing.

\section{Conclusion}

Epicardial fat may present an important link between chronic obstructive pulmonary disease and cardiovascular diseases, mainly coronary artery disease. Currently, the data available tends to support the hypothesis of a higher volume of $\mathrm{EF}$ in COPD patients with a possibly subsequent higher level of systemic inflammation. Measurement of EF thickness could present a novel approach to CVD risk stratification in patients with COPD. However, more robust data is needed.

\section{Conflict of interest}

The authors declare no conflict of interest.

\section{References:}

1. Zagaceta J, Zulueta JJ, Bastarrika G, et al. Epicardial adipose tissue in patients with chronic obstructive pulmonary disease. PLoS One. 2013; 8(6): e65593, doi: 10.1371/journal. pone.0065593, indexed in Pubmed: 23762399.

2. Rosito GA, Massaro JM, Hoffmann U, et al. Pericardial fat, visceral abdominal fat, cardiovascular disease risk factors, and vascular calcification in a community-based sample: the Framingham Heart Study. Circulation. 2008; 117(5): 605-613, doi: 10.1161/CIRCULATIONAHA.107.743062, indexed in Pubmed: 18212276.

3. Wong CX, Ganesan AN, Selvanayagam JB. Epicardial fat and atrial fibrillation: current evidence, potential mechanisms, clinical implications, and future directions. Eur Heart J. 2017; 38(17): 1294-1302, doi: 10.1093/eurheartj/ehw045, indexed in Pubmed: 26935271.

4. Thanassoulis G, Massaro JM, O'Donnell CJ, et al. Pericardial fat is associated with prevalent atrial fibrillation: the Framingham Heart Study. Circ Arrhythm Electrophysiol. 2010; 3(4): 345-350, doi: 10.1161/CIRCEP.109.912055, indexed in Pubmed: 20558845.

5. Salazar J, Luzardo E, Mejías JC, et al. Epicardial fat: physiological, pathological, and therapeutic implications. Cardiol Res Pract. 2016; 2016: 1291537, doi: 10.1155/2016/1291537, indexed in Pubmed: 27213076.

6. Çetin M, Kocaman S, Durakoğlugil M, et al. Effect of epicardial adipose tissue on diastolic functions and left atrial dimension in untreated hypertensive patients with normal systolic function. Journal of Cardiology. 2013; 61(5): 359-364, doi: 10.1016/j.jjcc.2012.12.015.

7. Mahajan R, Kuklik P, Grover S, et al. Cardiovascular magnetic resonance of total and atrial pericardial adipose tissue: a validation study and development of a 3 dimensional pericardial adipose tissue model. J Cardiovasc Magn Reson. 2013; 15: 73, doi: 10.1186/1532-429X-15-73, indexed in Pubmed: 24498950.

8. Nelson AJ, Worthley MI, Psaltis PJ, et al. Validation of cardiovascular magnetic resonance assessment of pericardial adipose tissue volume. J Cardiovasc Magn Reson. 2009; 11: 15, doi: 10.1186/1532-429X-11-15, indexed in Pubmed: 19416534.

9. Thanassoulis G, Massaro JM, O'Donnell CJ, et al. Pericardial fat is associated with prevalent atrial fibrillation: the Framingham Heart Study. Circ Arrhythm Electrophysiol. 2010; 3(4): 345-350, doi: 10.1161/CIRCEP.109.912055, indexed in Pubmed: 20558845. 
10. Mahabadi AA, Lehmann N, Kälsch H, et al. Association of epicardial adipose tissue and left atrial size on non-contrast CT with atrial fibrillation: the Heinz Nixdorf Recall Study. Eur Heart J Cardiovasc Imaging. 2014; 15(8): 863-869, doi: 10.1093/ ehjci/jeu006, indexed in Pubmed: 24497517.

11. Bertaso AG, Bertol D, Duncan BB, et al. Epicardial fat: definition, measurements and systematic review of main outcomes. Arq Bras Cardiol. 2013; 101(1): e18-e28, doi: 10.5935/ abc.20130138, indexed in Pubmed: 23917514.

12. Kaplan O, Kurtoglu E, Gozubuyuk G, et al. Epicardial adipose tissue thickness in patients with chronic obstructive pulmonary disease having right ventricular systolic dysfunction. Eur Rev Med Pharmacol Sci. 2015; 19(13): 2461-2467, indexed in Pubmed: 26214783.

13. Iacobellis G, Willens HJ. Echocardiographic epicardial fat: a review of research and clinical applications. J Am Soc Echocardiogr. 2009; 22(12): 1311-9; quiz 1417, doi: 10.1016/j. echo.2009.10.013, indexed in Pubmed: 19944955.

14. Iacobellis G, Ribaudo MC, Assael F, et al. Echocardiographic epicardial adipose tissue is related to anthropometric and clinical parameters of metabolic syndrome: a new indicator of cardiovascular risk. J Clin Endocrinol Metab. 2003; 88(11): 5163-5168, doi: 10.1210/jc.2003-030698, indexed in Pubmed: 14602744 .

15. Thanassoulis G, Massaro JM, O‘Donnell CJ, et al. Pericardial fat is associated with prevalent atrial fibrillation: the Framingham Heart Study. Circ Arrhythm Electrophysiol. 2010; 3(4): 345-350, doi: 10.1161/CIRCEP.109.912055, indexed in Pubmed: 20558845.

16. Yudkin JS, Eringa E, Stehouwer CDA. „Vasocrine“ signalling from perivascular fat: a mechanism linking insulin resistance to vascular disease. Lancet. 2005; 365(9473): 1817-1820, doi: 10.1016/S0140-6736(05)66585-3, indexed in Pubmed: 15910955.

17. Iacobellis G. Local and systemic effects of the multifaceted epicardial adipose tissue depot. Nat Rev Endocrinol. 2015; 11(6): 363-371, doi: 10.1038/nrendo.2015.58, indexed in Pubmed: 25850659 .

18. Schäffler A, Schölmerich J. Innate immunity and adipose tissue biology. Trends Immunol. 2010; 31(6): 228-235, doi: 10.1016/j.it.2010.03.001, indexed in Pubmed: 20434953.

19. Friedman JM. Obesity in the new millennium. Nature. 2000; 404(6778): 632-634, doi: 10.1038/35007504.

20. Greulich S, Chen W, Maxhera B. Cardioprotective properties of omentin- 1 in type 2 diabetes: evidence from clinical and in vitro studies. PLoS ONE. 2013; 8(3): e59697.

21. Sanchez F, Garcia R, Alarcon F. Adipocinas, tejido adiposo y su relaci 'on con c'elulas del sistema inmune. Gaceta Medica de Mexico. 2005; 141(6): 505-512.

22. Matsuda M, Shimomura I. Roles of oxidative stress, adiponectin, and nuclear hormone receptors in obesityassociated insulin resistance and cardiovascular risk. Hormone molecular biology and clinical investigation. 2014; 19(2): 75-88.

23. Bastard JP, Maachi M, Lagathu C. Recent advances in the relationship between obesity, inflammation, and insulin resistance. European Cytokine Network. 2006; 17(1): 4-12.

24. Ichiki Y, Kitamura K, Kangawa K. Distribution and characterization of immunoreactive adrenomedullin in human tissue and plasma. FEBS Letters. 1994; 338(1): 6-10.

25. Lima M, Torres C, Rosa F. Adrenomedulina: żm 'as que una simple hormona? Revista Venezolana de Endocrinolog'ı y Metabolismo. 2011; 1: 4-11.

26. Kang YS. Obesity associated hypertension: new insights into mechanism. Electrolyte and Blood Pressure. 2013; 11(2): 46.

27. Baker AR, Harte AL, Howell N, et al. Epicardial adipose Tissue as a Source of Nuclear Factor- $\kappa$ B and c-Jun N-Terminal Kinase Mediated Inflammation in Patients with Coronary Artery Disease. The Journal of Clinical Endocrinology \& Metabolism. 2009; 94(1): 261-267, doi: 10.1210/jc.2007-2579.

28. Klouche M, Bhagdi S, Hemmes M. Rose-John, Novel path to activation of vascular smooth muscle cells: upregulation of gp130 creates an autocrine activation loop by IL-6 and its soluble receptor. The Journal of Immunology. 1999; 163(8): 4583-4589.

29. Sanchez FS, Garcia S, Alarcon F, et al. Adipocinas, tejido adiposo y su relaci 'on con c'elulas del sistema inmune. Gaceta Medica de Mexico. 2005; 141(6): 505-512.

30. Zhang H, Park Y, Wu J et al. Role of TNF- in vascular dysfunction. Clinical Science. 2009; 116(3): 219-230. doi: 10.1042/ CS20080196.

31. Maenhaut N, Van de Voorde J. Regulation of vascular tone by adipocytes. BMC Medicine. 2011; 9(25): 12. https://doi. org/10.1186/1741-7015-9-25

32. Ito T, Nasu K, Terashima $\mathrm{M}$ et al., The impact of epicardial fat volume on coronary plaque vulnerability: insight from optical coherence tomography analysis. European Heart Journal Cardiovascular Imaging. 2012; 13(5): 408-415. https://doi. org/10.1093/ehjci/jes022

33. Yerramasu A, Dey D, Venuraju S et al., Increased volume of epicardial fat is an independent risk factor for accelerated progression of sub-clinical coronary atherosclerosis. Atherosclerosis. 2012; 220(1): 223-230. doi: 10.1016/j.atherosclerosis.2011.09.041

34. Okada K, Ohshima S, Isobe S et al., Epicardial fat volume correlates with severity of coronary artery disease in nonobese patients. Journal of Cardiovascular Medicine. 2014; 15(5): 384-390. doi: 10.2459/JCM.0b013e32836094da.

35. Demircelik MB, Yilmaz OC, Gurel OM et al. Epicardial adipose tissue and pericoronary fat thickness measured with 64-multidetector computed tomography: potential predictors of the severity of coronary artery disease. Clinics. 2014; 69(6): 388-392. 10.6061/clinics/2014(06)04

36. Wong CX, Sun MT, Odutayo A et al. Associations of Epicardial, Abdominal, and Overall Adiposity With Atrial Fibrillation. Circ Arrhythm Electrophysiol. 2016; 9(12): e004378.

37. Thanassoulis G, Massaro JM, O'Donnell CJ et al. Pericardial fat is associated with prevalent atrial fibrillation: the Framingham Heart Study. Circ Arrhythm Electrophysiol. 2010; 3: 345-350. doi: 10.1161/CIRCEP.109.912055.

38. Salgado-Somoza A, Teijeira-Fernandez E. et al. Proteomic analysis of epicardial and subcutaneous adipose tissue revers differences in proteins involved in oxidative stress. Am J Physiol Heart Circ Physiol. 2010; 299: 202-209. doi: 10.1152/ ajpheart.00120.2010.

39. Chen PS, Chen LS, Fishbein MC, et al. Role of the autonomic nervous system in atrial fibrillation: pathophysiology and therapy. Circ Res. 2014; 114: 1500-1515. doi: 10.1161/CIRCRESAHA.114.303772

40. Oh S, Zhang Y, Bibevski S et al. Vagal denervation and atrial fibrillation inducibility: epicardial fat pad ablation does not have long-term effects. Heart Rhythm. 2006; 3: 701-708.

41. Ding J, Hsu FC, Harris TB, et al. The association of pericardial fat with incident coronary heart disease: the Multi-Ethnic Study of Atherosclerosis (MESA). Am J Clin Nutr. 2009; 90 : 499-504. doi: 10.3945/ajcn.2008.27358

42. van den Borst B, Gosker HR, Schols AM. Central fat and peripheral muscle: partners in crime in chronic obstructive pulmonary disease. Am J Respir Crit Care Med. 2013; 187(1): 8-13. doi: 10.1164/rccm.201208-1441OE.

43. van den Borst B, Gosker HR, Koster A et al. The influence of abdominal visceral fat on inflammatory pathways and mortality risk in obstructive lung disease. Am J Clin Nutr. 2012; 96: 516-526. doi: 10.3945/ajcn.112.040774

44. Kiraz K, Gökdeniz T, Kalaycıoglu E, et al. Epicardial fat thickness is associated with severity of disease in patients with chronic obstructive pulmonary disease. Eur Rev Med Pharmacol Sci. 2016;20(21):4508-4515. PMID:27874948

45. Demir M, Acet H, Kaya $\mathrm{H}$ et al. Relationship between metabolic syndrome and epicardial fat tissue thickness in patients with chronic obstructive pulmonary disease. Anatol J Cardiol. 2016;16(6):405-411. doi: 10.14744/AnatolJCardiol.2016.7211 